\title{
IMAGINARY-a How-to Guide for Math Exhibitions
}

\author{
Andreas Daniel Matt
}

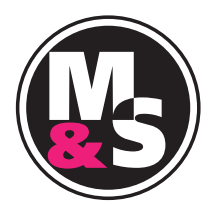

Not so long ago, mathematicians debated the question of why they should communicate about their subject to a broad public. Today, we seem to have collected enough good reasons why and can pass on to the next question: How can we communicate about mathematics to a broad public?

In this article I offer answers to this question in the form of a hands-on guide to planning and organizing interactive mathematics exhibitions. The guide draws on experience from almost ten years of organizing such exhibitions in more than fifty countries, under the umbrella of a project called IMAGINARY. Mathematics and Statistics Awareness Month, celebrated in the US each year in April, provides the perfect occasion to jump in and organize a math exhibition. IMAGINARY can provide a wealth of ideas and resources to get you started.

\begin{abstract}
Math Communication on the Rise
All over the globe, new ways of communicating about mathematics are mushrooming.

New math museums are popping up. Mathematicians produce movies, mobile apps, 3-dimensional prints, and visualizations. They give talks, conduct workshops, visit schools, and write popular books. Math communication conferences are being held on all continents. Mathematical research projects often include outreach components, and math research centers are hiring dedicated outreach mathematicians. More and more professional math communicators are earning a living through this work. There are even independent math communication companies and organizations. A new booming field is arising!
\end{abstract}

Andreas Daniel Matt is the managing director of the nonprofit organization IMAGINARY, based in Berlin, which provides international services for mathematics outreach projects. His e-mail address is andreas . matt@imaginary.org.

For permission to reprint this article, please contact: reprint-permission@ams . org.

DOI: http://dx.doi.org/10.1090/noti1508

\section{IMAGINARY}

IMAGINARY started as a mathematics traveling exhibition for the German Year of Mathematics in 2008. It was a project of the Mathematisches Forschungsinstitut Oberwolfach (MFO), initiated and organized by former MFO director Gert-Martin Greuel and me. The exhibition contained a collection of state-of-the-art mathematical visualizations and interactive programs. One, called SURFER, allows one to experience and explore the relationship between formulas and forms [1].

The exhibition was a big success. With increasing interest from universities, research institutes, and schools, we decided to offer the exhibition through an open license, called an "open science exhibition," which operates in a way similar to open software [2]. Everybody can copy IMAGINARY exhibits and create their own IMAGINARY exhibitions. So far, IMAGINARY exhibitions and events have been staged in collaboration with local partners (mainly mathematicians) in more than one hundred fifty cities, fifty-two countries, and twenty-five languages.

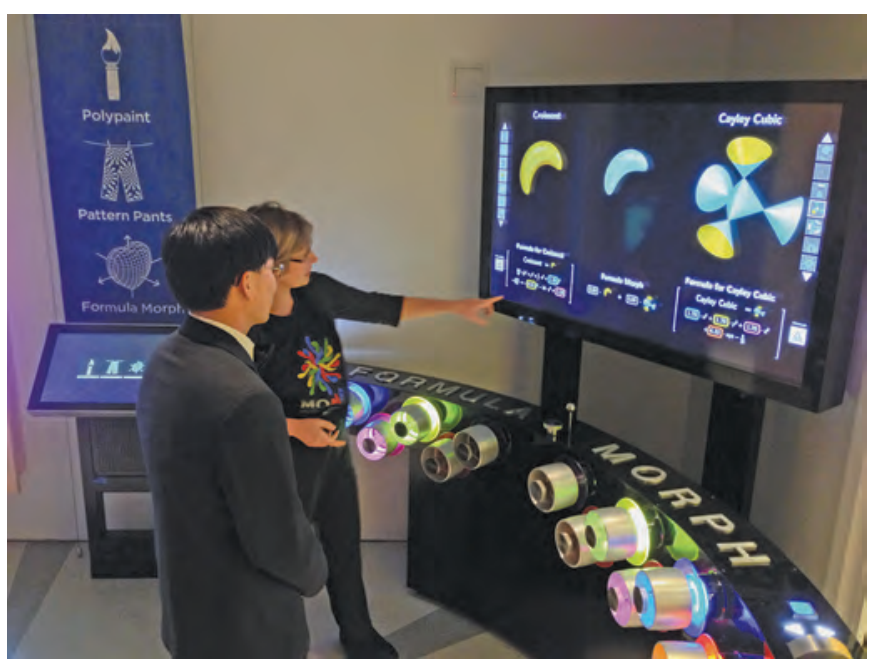

An algebraic geometry exhibit in collaboration with IMAGINARY at the Museum of Mathematics in New York City. 


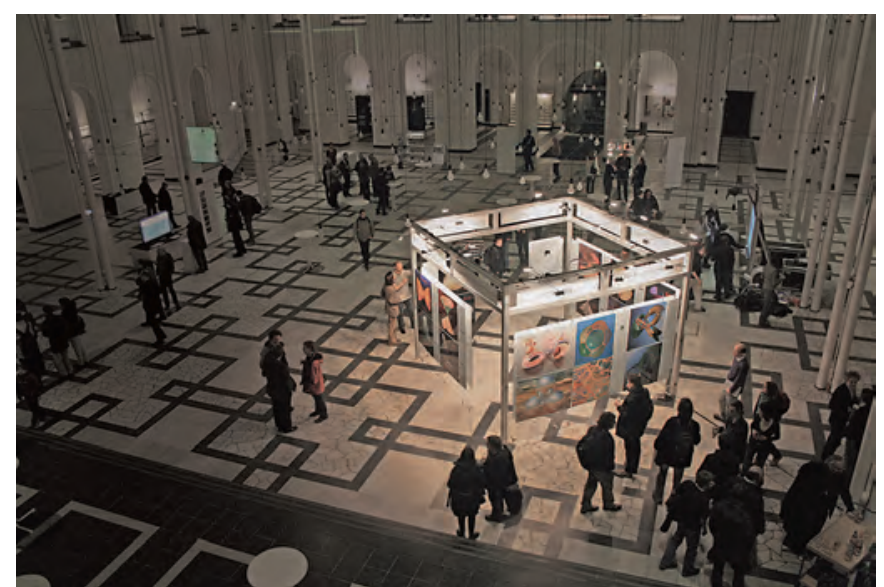

IMAGINARY exhibition in Hannover, Germany, 2009.

There are more than ten permanent IMAGINARY museum installations, for example, at the Deutsches Museum in Munich, one of the world's oldest and largest science and technology museums, and the Museum of Mathematics in New York City.

More than 2.5 million people have visited an IMAGINARY exhibition, and many more have downloaded modules and background material from the website www.imaginary.org. This platform hosts information about mathematics outreach events and includes computer programs, picture galleries, hands-on exhibits, films, and texts, as well as fully developed exhibitions. The platform also allows people to add new exhibits, and this has stimulated a large international community and network for knowledge transfer in mathematics.

Examples of collaborations stimulated by IMAGINARY include exhibitions in ten Russian cities on the occasion of the German-Russian Year of Education, Science and Innovation, 2011-2012. Since 2010, institutions in such countries as Spain, Belgium, the Netherlands, Uruguay, France, Taiwan, and South Korea have adopted the IMAGINARY idea, established local teams, and organized nationwide traveling exhibitions. These efforts are continuing in 2017 and 2018 and will be further extended with new exhibits and activities.

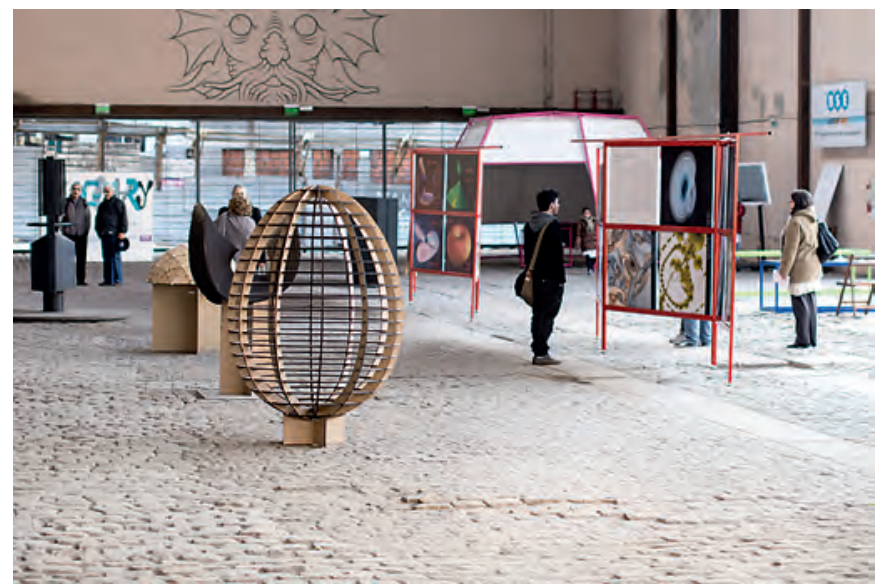

IMAGINARY exhibition in Montevideo, Uruguay, 2015.
A collaboration with the African Institute for Mathematical Sciences (AIMS) was launched in 2014, focusing on mathematics popularization on the African continent. It began with an IMAGINARY event in Dar-Es-Salaam, Tanzania, and continued with workshops, exhibitions, and road shows in Cape Town, South Africa, and in Dakar/M'Bour, Senegal. Further exhibitions are planned in Cape Verde, Mozambique, Democratic Republic of Congo, and Rwanda.

IMAGINARY has grown into a worldwide network of partners and individuals, with many international exhibitions and related events. In this way IMAGINARY has become a hub for transferring mathematical knowledge to society. Three key features of the project stand out: (1) it is close to mathematics research and mathematicians; (2) it is international and multilingual; and (3) it is free, open access, and open source. In addition, IMAGINARY offers physical and interactive content (online and offline) and tries to be as appealing, aesthetic, and advanced in its design as possible. All IMAGINARY activities are highly interactive and participative, involving mathematical and non-mathematical audiences in the creation of exhibitions.

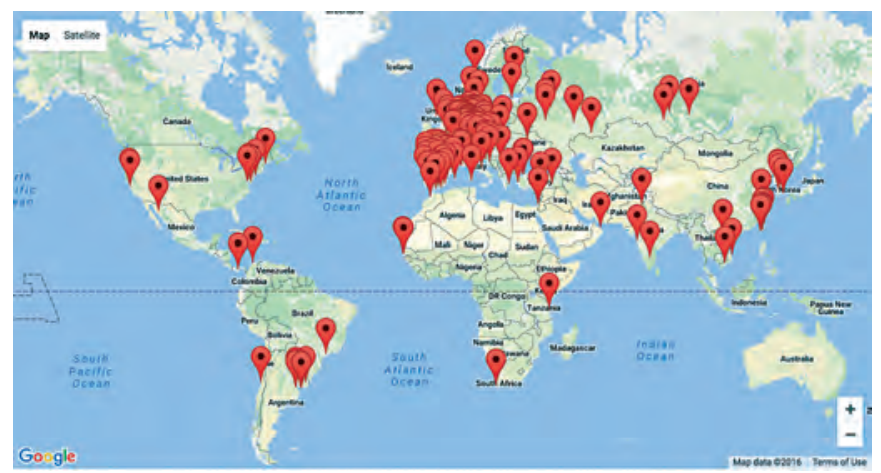

IMAGINARY activities have been organized in more than fifty countries.

Recently, IMAGINARY was organized as an independent nonprofit organization, with support by the Leibniz Association and the Klaus Tschira Foundation. The MFO remains a shareholder of the new organization, which is managed by all former project members.

\section{Stage a Mathematics Exhibition}

To get started planning a mathematics exhibition, you must resolve three main issues: the venue, the budget, and the exhibits. We recommend starting by selecting the venue. The venue often decides the dates of the exhibition and implies the type of audience. It also sets the exhibition space and thus the number of exhibits needed and the budget required. Venues should be attractive and easy to reach and should suit your target audience. They can be colleges or universities, art galleries, schools, public squares, train stations, shopping malls, bank foyers, etc. Often the venues are provided for free in return for co-sponsorship of the exhibition.

The budget for the whole exhibition could vary from US $\$ 2,000$ to US $\$ 200,000$ and depends mainly on whether 


\section{COMMUNICATION}

you use paid personnel or volunteers and on the quantity and quality of the exhibits. Usually the costs are covered partly by the host organization-for example, your college or university-in collaboration with outside partners or sponsors. Typical sponsors are banks, telecommunications firms, high tech companies, and foundations and organizations that promote science and education. Sometimes national or local governments contribute funds.

We classify four forms of exhibits:

- Program: an interactive software exhibit, often used on a touch screen

- Hands-on: a physical exhibit that can be manipulated or a 3-dimensional printed sculpture

- Film: a video that can be shown in an exhibition, for example, in a dedicated cinema room

- Image gallery: a collection of images accompanied by mathematical descriptions.

Ideally, an exhibition lets visitors immerse themselves in a new world. On the IMAGINARY platform you

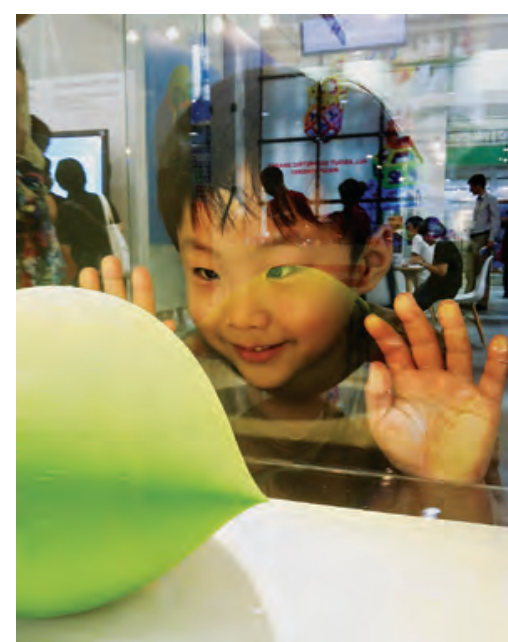

3D-printed algebraic surface at the NIMS-IMAGINARY exhibition during the ICM2014 in Seoul, South Korea.

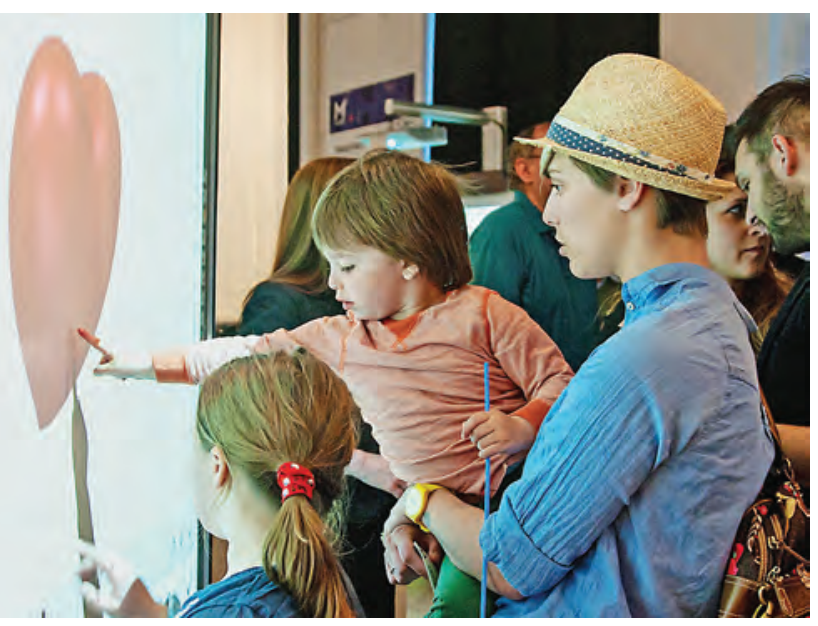

SURFER exhibit on a touch screen at IMAGINARY Belgrade, 2012.

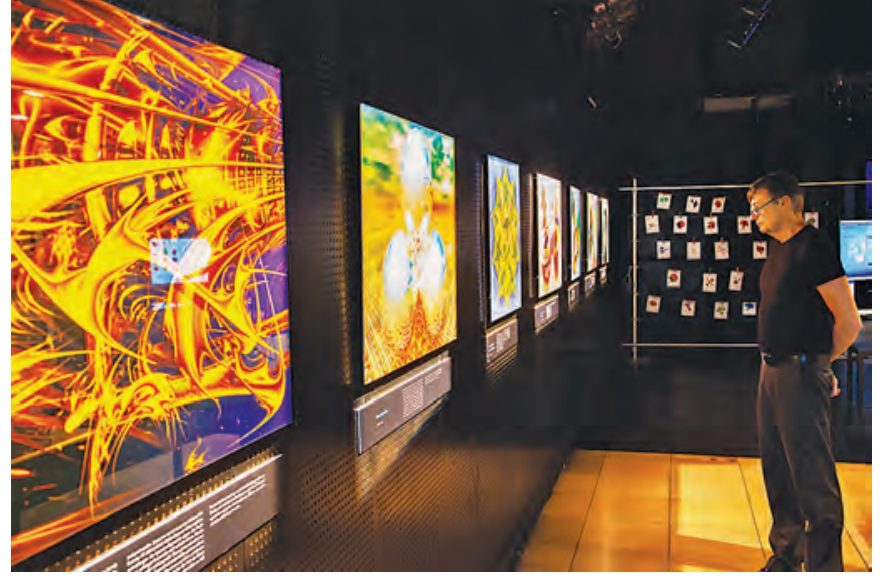

IMAGINARY exhibition at Heidelberg, Germany, with pictures printed in high quality by Luc Benard, Uli Gaenshirt, and Richard Palais, 2014.

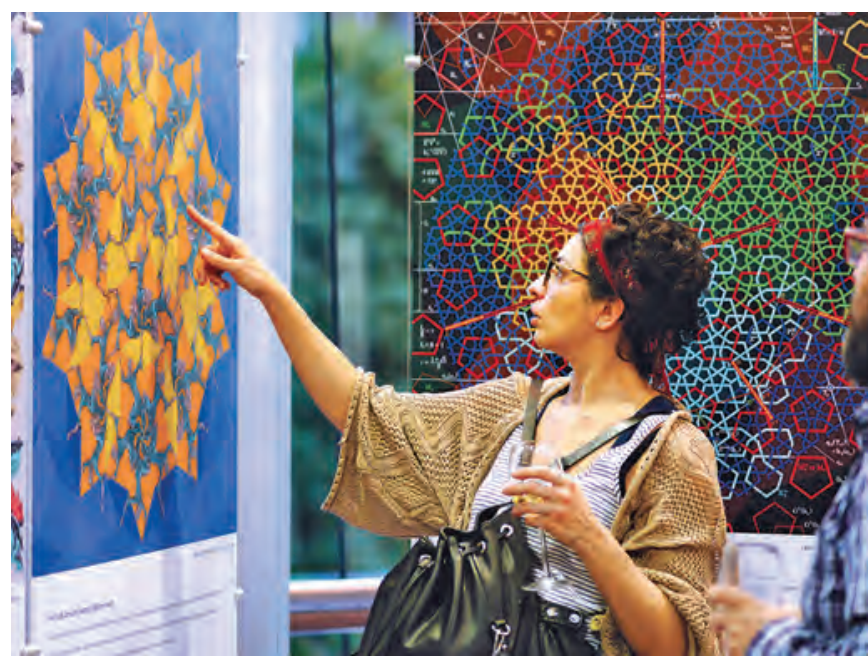

IMAGINARY image gallery on quasiperiodic tilings by Uli Gaenshirt at an exhibition in Istanbul coordinated by IMAGINARY Turkey, 2015.

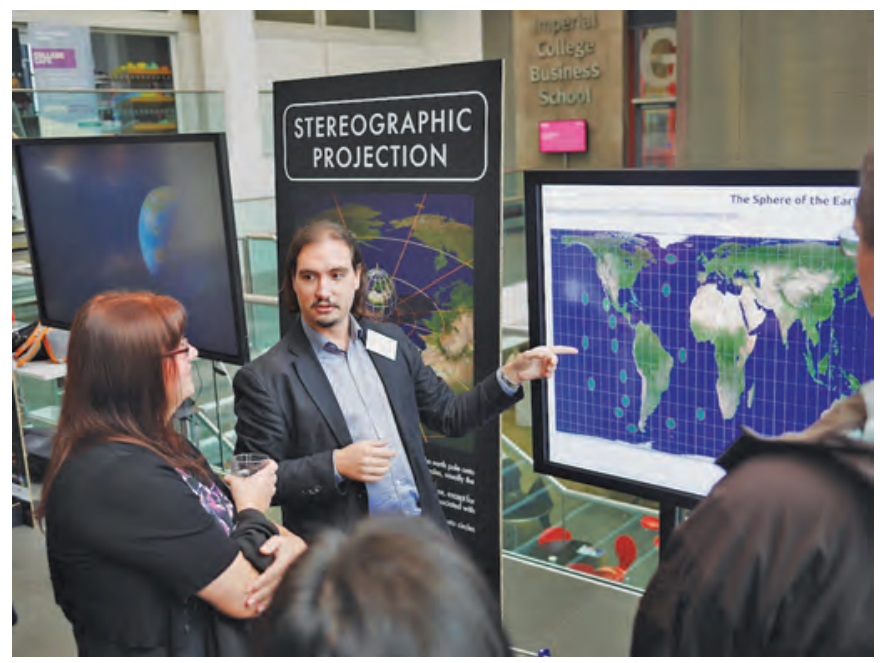

Interactive exhibit "Sphere of the Earth" with explainer at the MPE exhibition, Imperial College London, 2015. 
singularities, as well as explanations. Visitors can print their creations and add them to a user gallery at the exhibition and/or take the images home. Image galleries, video animations, and 3-dimensional printed sculptures of algebraic surfaces make great accompaniments for SURFER. The program can be used to stage online image competitions held parallel to the exhibition and can also be used in schools after the exhibition is over.

A special type of exhibit is the collection of "snapshots of modern mathematics" (see also [3]). These are short papers written by participants of workshops held at the MFO. The idea is to explain as accessibly and understandably as possible suitable topics from their research areas. The snapshots are then edited and shared under an open license. IMAGINARY offers a touch screen station to show these short texts during an exhibition, with an option to print them or e-mail them. By giving a glimpse into ongoing current research, they can give mathematical depth to your exhibition.

Once the venue, budget, and exhibits are set, you step into production and media work. To produce the exhibits, you either have to hire a company or buy the technology yourself. Often colleges and universities already have touch screens and computers that you can borrow. We recommend printing images in high quality and mounting them using a gallery system rather than affixing poster prints to walls. Media work can be carried out through your institution's public relations office or with assistance of IMAGINARY's media channels.

During the exhibition, guided tours can be offered, and you should arrange for tutors to be available on-site to explain the mathematical content. This makes a huge difference! Human explainers, who are often motivated students, inspire the visitors, and together they can explore the mathematics behind the exhibits. IMAGINARY offers special tutorials and training material for tutors.

Once the exhibition is over, the exhibits can be permanently installed in your institution or a local science museum.

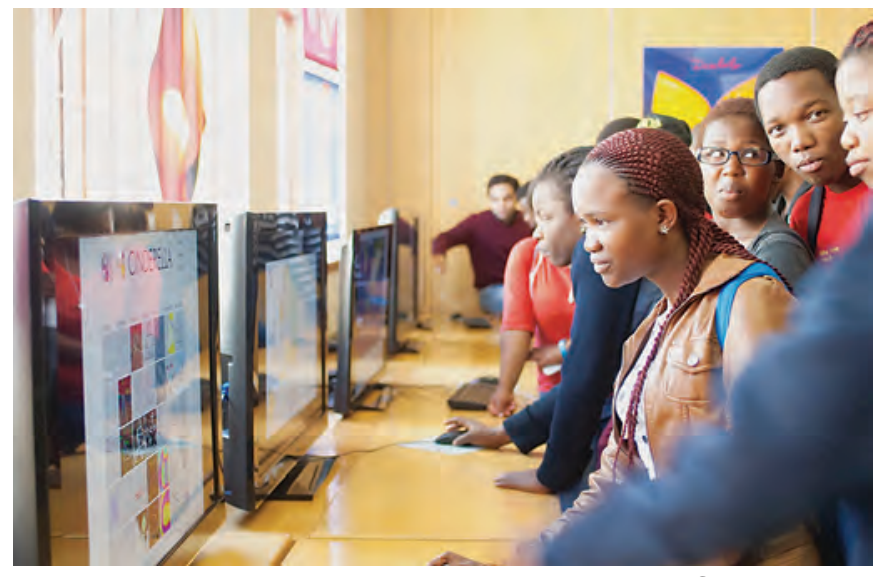

AIMS-IMAGINARY exhibition and workshop for math communicators, Cape Town, 2014.

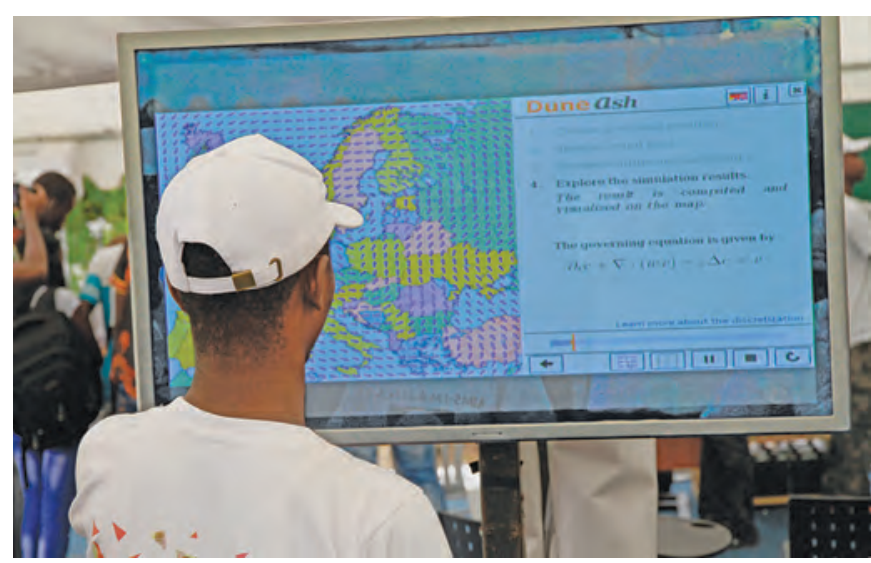

Interactive exhibit Dune Ash at the AIMS-IMAGINARY exhibition in M'bour in Senegal, 2015. It simulates, in real time, the dispersion of volcanic ash from a userchosen volcano location in the presence of a wind field that is drawn by hand.

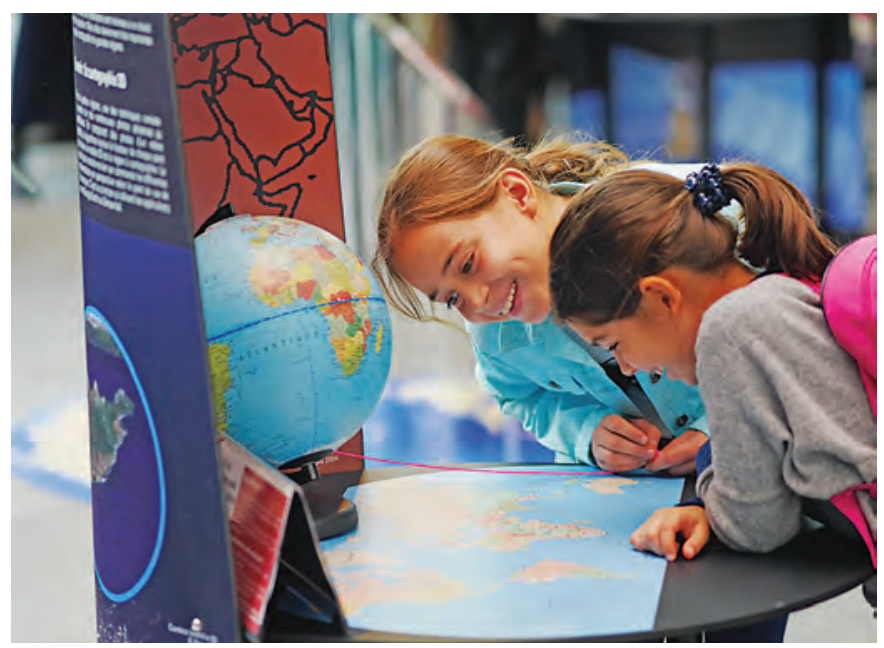

Hands-on exhibit on cartography of the MPE exhibition, Imperial College London, 2015.

\section{Create a Mathematics Exhibit}

An exhibition should always include local content. This means that you or your partner institution should try whenever possible to add your own ideas and your own flair to the exhibition. For example, you can prepare or enhance mathematical visualizations, films, or software simulations for the exhibition.

We have collected many hints about how mathematical knowledge can be transferred to an exhibit. Tools are available to create images in high resolution; movies can be made with digital cameras, via stop motion, or through animation; and 3-dimensional prints can be made at your institution or ordered online in very high quality at affordable prices.

You can then share your exhibit under an open license, which means that your exhibit can then be duplicated at other exhibitions. This way, the collection of available content is constantly changing and evolving, and we all benefit from each other's ideas. In this sense, IMAGINARY 


\section{COMMUNICATION}
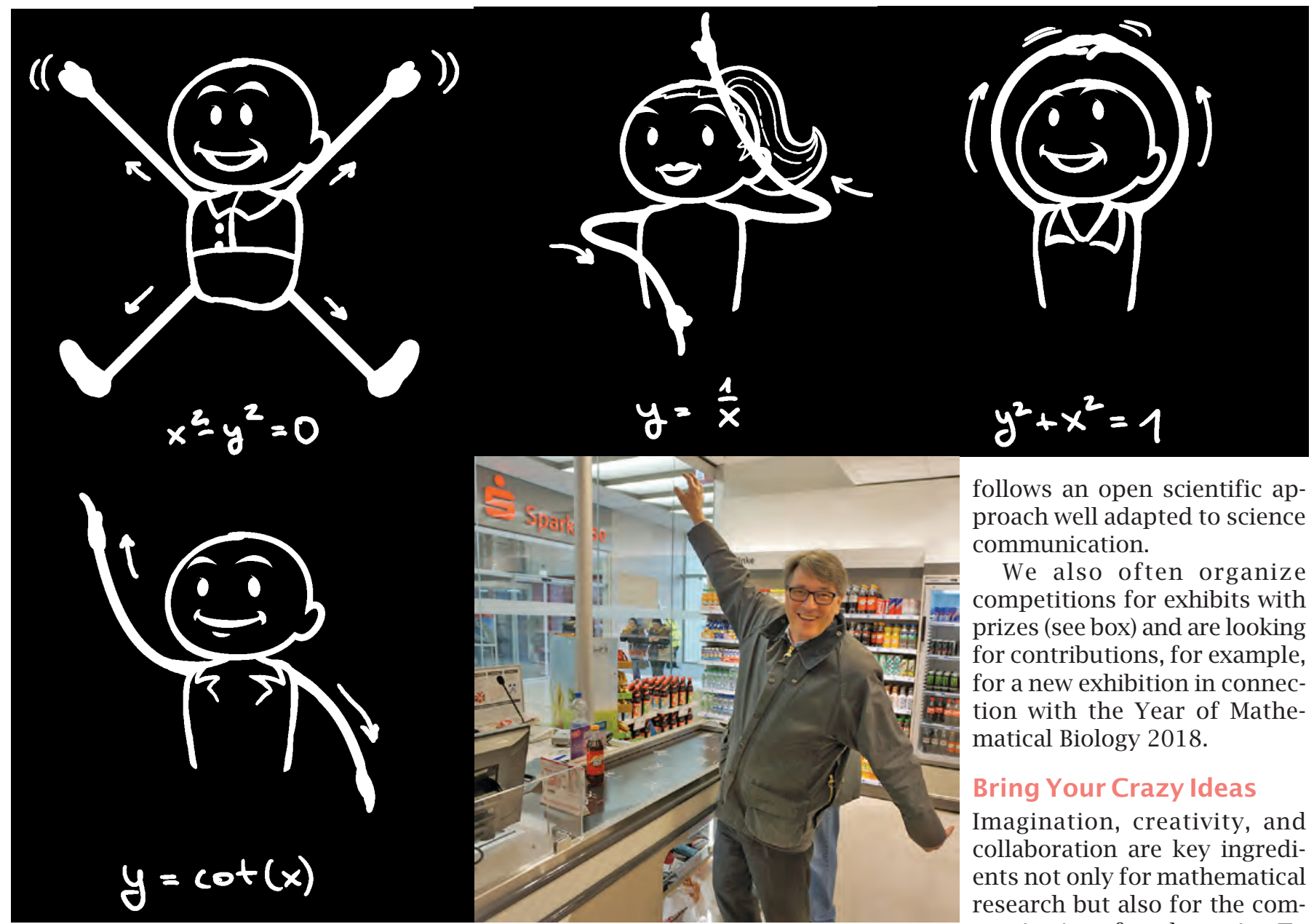

follows an open scientific approach well adapted to science communication.

We also often organize competitions for exhibits with prizes (see box) and are looking for contributions, for example, for a new exhibition in connection with the Year of Mathematical Biology 2018.

\section{Bring Your Crazy Ideas}

Imagination, creativity, and collaboration are key ingredients not only for mathematical research but also for the communication of mathematics. To successfully reach and involve a large audience, we recommend thinking "outside the

\section{Join the Mathematics of Planet Earth Competition!}

Participate in the new competition of exhibition modules for Mathematics of Planet Earth (MPE). You can submit exhibits designed to showcase the ways in which the mathematical sciences can be useful in tackling our world's problems. The best modules will receive prizes and will enrich the successful MPE exhibition. There is a special prize for Africa-related exhibits.

The competition is organized by UNESCO, the International Mathematical Union, the International Commission on Mathematical Instruction, and IMAGINARY.

1st prize: US $\$ 5,000$

2nd prize: US\$2,000

3rd prize: US\$1,000

Special prize for African topic: US\$2,000

Submission Deadline: June 30, 2017

More information at www.imaginary.org/mpe -competition. box." Crazy ideas are welcome!

In IMAGINARY activities, we have seen many creative inventions, which are often initiated in collaboration with artists, designers, musicians, or even chefs-

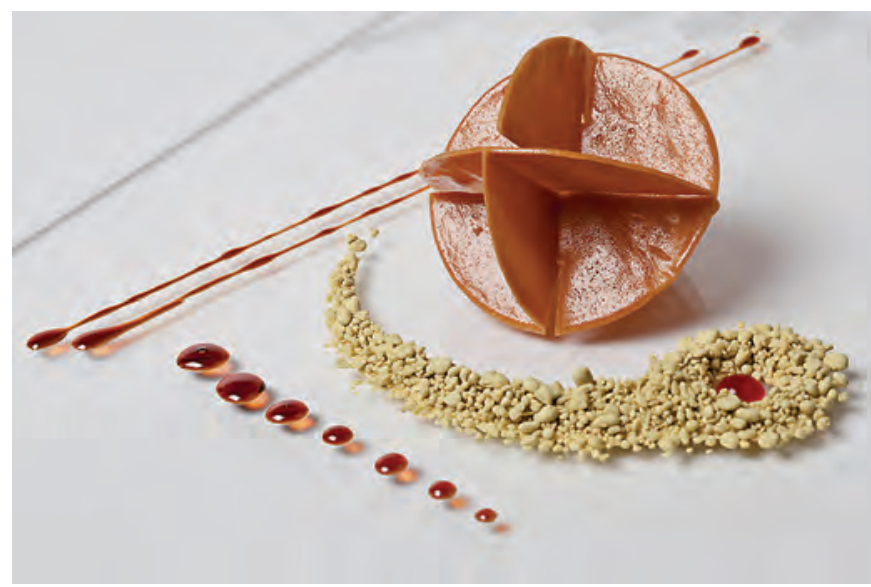

Picture from the exhibition "The Taste of Mathematics," 2012. 
people who visited our exhibitions and got inspired. One example started with the question, How does math taste? Michelin-starred chef José Carlos García teamed up with mathematician Mercedes Siles Molina and photographer Pedro Reyes Dueñas (all three from Malaga) to compare the creative process of cooking with the creative process of doing mathematics. The results are pictures of a mathematical menu and an exhibition plus documentation of the worlds of cooking and doing math. They were inspired by the IMAGINARY exhibition organized in Spain by the Real Sociedad de Matemática Española.

What are the best venues for exhibitions? Surprising venues, like shopping malls, where you would not expect to encounter math, work wonderfully. A prime example is the mathematics-themed shopping mall called Mathematikon Shops that opened in Heidelberg in February 2016. In collaboration with mathematicians from fourteen countries, IMAGINARY equipped the shopping mall-including the conveyor belts, the parking lot, and the restrooms-with mathematical images, puzzles, sculptures, and a huge multitouch interactive station [4].

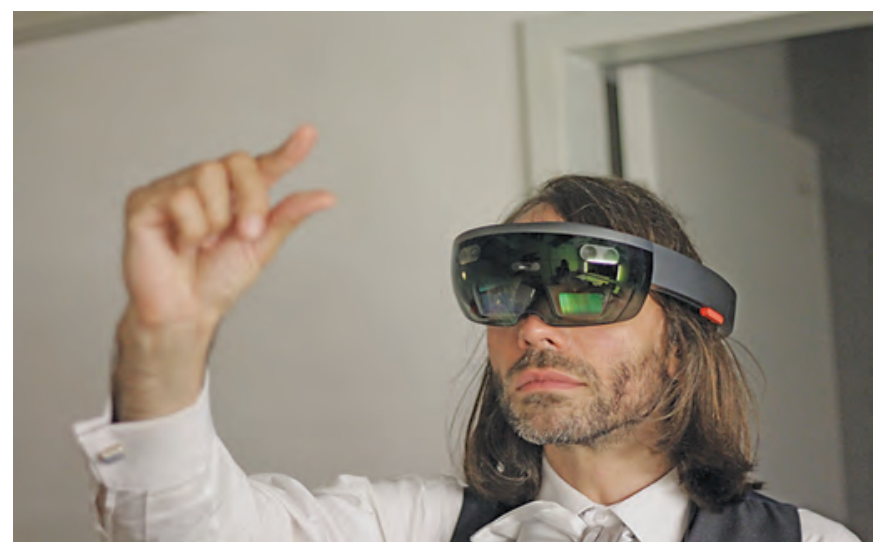

Mathematician Cédric Villani exploring augmented reality for math museums in the holo-math.com project, 2016.

How can new technology be used in mathematics museums? The Holo-Math project initiated by Cédric Villani, director of the Institut Henri Poincaré, in collaboration with IMAGINARY and tech partners, explores how augmented reality can be used to explain and explore mathematical insights. Museum visitors are equipped with HoloLens devices and introduced to mathematically augmented worlds. The first episode of a Holo-Math adventure on Brownian motion is now being finalized.

\section{Stay Connected}

If you want to be informed about current mathematics exhibitions or trends in mathematics communication, please join the Mathematics Communication Network (imaginary.org/network). You can subscribe to its newsletter and participate in joint projects and conferences. To find out about international mathematics outreach projects, including museums, exhibitions, and events, please visit wi kimathcom. imaginary.org, a WikiPage dedicated exclusively to mathematics communication.

If you want to organize an IMAGINARY exhibition and would like support, feel free to contact me. If you organize an exhibition, please announce your event to the online listing of all exhibitions at imaginary.org/events. There you can also find out about all current exhibitions and museum installations, including ones happening in the coming months in Brazil, Germany, the Netherlands-and maybe a place near you!

\section{Credits}

Photos of the IMAGINARY exhibition in Hannover, the world map, the 3D-printed algebraic surface in Seoul, the exhibition in Belgrade, the image gallery in Istanbul, the exhibition and workshop in Cape Town, the interactive exhibit in M'bour, the hands-on exhibit in London, the algebraic geometry exhibit in New York, the math dance in Heidelberg, and the Holo-Math project are courtesy of IMAGINARY.

Photo of the IMAGINARY exhibition in Montevideo courtesy of Matu Tejera.

Photo of the IMAGINARY exhibition in Heidelberg courtesy of Heidelberg Laureate Forum Foundation.

Photo from the exhibition "The Taste of Mathematics" courtesy of Pedro Reyes Dueñas.

Illustrations of dancing functions courtesy of Michael Gralmann. Photo of Andreas Daniel Matt courtesy of Andreas Daniel Matt.

ACKNOWLEDGMENT . For feedback and assistance with the article: Bianca Violet, Nadja Pernat, Gert-Martin Greuel, and Christian Stussak.

\section{References}

[1] G.-M. GREUEL and A. D. MATT (eds.), IMAGINARY-Through the Eyes of Mathematics, Travelling Exhibition Catalogue, published by the Mathematisches Forschungsinstitut Oberwolfach, ISBN: 9-783000-269394, 2008.

[2] A. D. MATT, IMAGINARY and the idea of an open source math exhibition platform, in E. Behrends et al. (eds.), Raising Public Awareness of Mathematics, Springer-Verlag, Berlin-Heidelberg, 2012, DOI 10.1007/978-3-642- 25710-0_26.

[3] C. CEDERbAum and A. CoOPER, Snapshots of modern mathematics from Oberwolfach: Writing about mathematics for a wide audience, Notices of the AMS 63 (2016), no. 8.

[4] B. VIOLET and A. D. MATT, Mathematikon: A mathematical shopping center, Proceedings of Bridges Conference, Jyväskylä, August 2016. 


\section{COMMUNICATION}

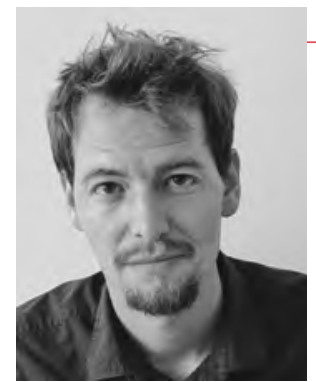

Andreas Daniel Matt

\section{ABOUT THE AUTHOR}

A co-founder of IMAGINARY, Andreas Daniel Matt worked as mathematics communicator at the Mathematisches Forschungsinstitut Oberwolfach from 2007 until 2016. He studied mathematics and computer science and did his PhD in mathematics in machine learning at the University of Innsbruck and the University of Buenos Aires. He curated the MiMa, a museum for minerals and mathematics in Oberwolfach, and is a member of the Raising Public Awareness Committee of the European Mathematical Society. He has received several prizes for his outreach activities, including the Media Prize of the German Mathematical Society in 2013 (together with Gert-Martin Greuel) for the IMAGINARY project.

\section{AMS on Social Networks}

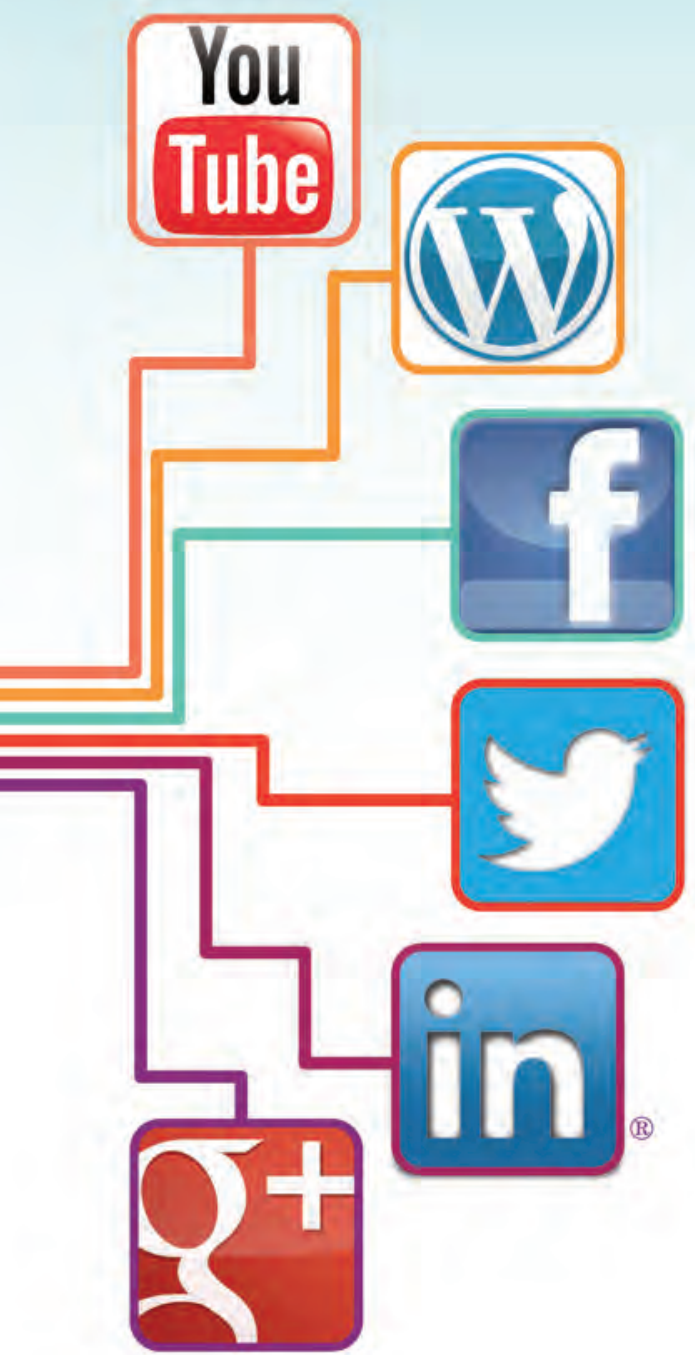

As part of the Society's commitment to the open flow of communication and community engagement, the AMS uses several networking tools to supplement the channels currently in place for members, press and the general public.

We invite you to share AMS website content and set up RSS feeds for website updates and blogs.

www.ams.org/social 